WRI-01-R010

\title{
PRODUCTION WELL WATER SHUT-OFF TREATMENT IN A HIGHLY FRACTURED SANDSTONE RESERVOIR
}

Final Report

By

Lyle A. Johnson Jr.

July 2001

Work Performed Under Cooperative Agreement DE-FC26-98FT40323 Task 20

For

Equity Oil Company

Salt Lake City, Utah

And

U.S. Department of Energy

National Energy Technology Laboratory

Morgantown, West Virginia 


\section{DISCLAIMER}

This report was prepared as an account of work sponsored by an agency of the United States Government. Neither the United States Government nor any agency thereof, nor any of their employees, makes any warranty, expressed or implied, or assumes any legal liability or responsibility for the accuracy, completeness, or usefulness of any information, apparatus, product, or process disclosed, or represents that its use would not infringe on privately owned rights. Reference herein to any specific commercial product, process, or service by trade name, trademark, manufacturer, or otherwise does not necessarily constitute or imply its endorsement, recommendation, or favoring by the United States Government or any agency thereof. The views and opinions of authors expressed herein do not necessarily state or reflect those of the United States Government or any agency thereof. 


\begin{abstract}
As domestic oil and gas fields approach maturity or even abandonment, new methods are being tested to add life to the fields. One area being addressed is the reduction of water production to extend the economic life of a field. In many fields a very common problem is permeability heterogeneity from matrix variations, fractures, or both. Conventional procedures to remediate high water rates in fractured networks, including cement squeezing, openhole packers, and liners are generally unsuccessful. The objective of this project was to test the viability of using sequential treatment of a production well with a cross-linked polymer to restrict water production from highly permeable and fractured zones. The field used for testing was the Ashley Valley field in northeastern Utah.

The process proposed for testing in this field was the sequential application of small batches of a cross-linked polymer, chromium (III) polyacrylamide polymer (MarcitK ). First, the highest permeability fractures were to be blocked, followed progressively by smaller fractures, and finally the higher permeability matrix channels. The initial application of this polymer in September 1997 in the Ashley Valley (AV) well \#2 did increase oil production while decreasing both water production and the relative permeability to water. The successive application of the polymer was considered as a method to increase both daily and ultimate oil production and reduce produced water.
\end{abstract}

The second polymer treatment was conducted in October 1999 in AV \#2. The treatment consisted of 4,994 barrels of 1,500-mg/l to 9,000-mg/l polymer at surface injection pressures no higher than 380 psig. During injection, four offset wells showed polymer breakthrough and were shut in during the remaining treatment.

Present oil and water production rates for AV \#2 are 14 BOPD and 2,700 BWPD, which is a $44 \%$ decrease in the oil rate and a $40 \%$ reduction in water from the rates after the first treatment. The decrease in water production did result in a minimal savings on both utilities and water-treatment chemicals. However, the savings did not offset the decrease in oil production. The second treatment appears to have targeted a different, high-permeability network than the first treatment, indicating that the first treatment was still effective after two years.

Because of the negative results from the second treatment, the conduct of a third treatment has been shelved. The possibility of a larger treatment in another well with the shut in of adjacent wells as the polymer is detected is being considered if further treatment is conducted. 


\section{TABLE OF CONTENTS}

\section{$\underline{\text { Page }}$}

LIST OF TABLES AND FIGURES $\ldots \ldots \ldots \ldots \ldots \ldots \ldots \ldots \ldots \ldots \ldots \ldots$

EXECUTIVE SUMMARY $\ldots \ldots \ldots \ldots \ldots \ldots \ldots \ldots \ldots \ldots \ldots$ vi

INTRODUCTION $\ldots \ldots \ldots \ldots \ldots \ldots \ldots \ldots \ldots \ldots \ldots \ldots \ldots \ldots \ldots \ldots \ldots \ldots \ldots \ldots$

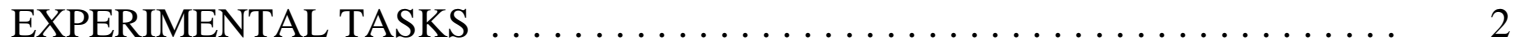

Test Design and Well Preparation $\ldots \ldots \ldots \ldots \ldots \ldots \ldots \ldots \ldots \ldots \ldots$

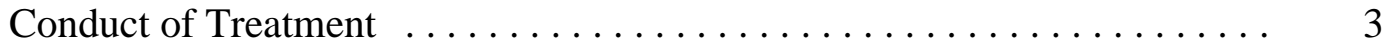

Monitoring of Treatment $\ldots \ldots \ldots \ldots \ldots \ldots \ldots \ldots \ldots \ldots \ldots \ldots$

RESULTS AND DISCUSSION $\ldots \ldots \ldots \ldots \ldots \ldots \ldots \ldots \ldots \ldots \ldots \ldots$

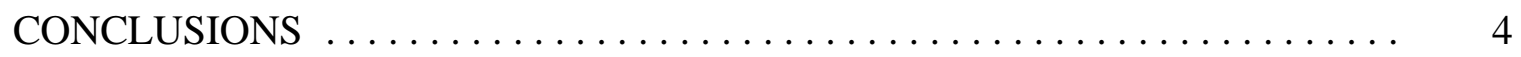

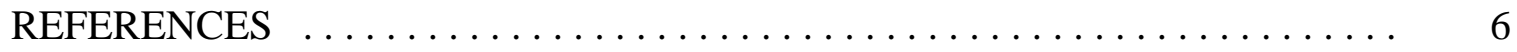




\section{LIST OF TABLES AND FIGURES}

$\underline{\text { Table }}$

Page

1. Planned and Actual Treatment Protocols for Ashley

Valley Polymer Application $\ldots \ldots \ldots \ldots \ldots \ldots \ldots \ldots \ldots \ldots \ldots \ldots \ldots \ldots \ldots \ldots \ldots$

Figure

1. Ashley Valley Field (Larson, et al. 1999) . . . . . . . . . . . . . . . . . . 8

2. Average Daily Oil Production, Ashley Valley \#2 . . . . . . . . . . . . . 9

3. Average Daily Water Production, Ashley Valley \#2 ............... 10

4. Pressure Profile for Second Polymer Treatment, Ashley Valley Field ...... 11

5. Average Daily Oil Production, Ashley Valley \#4 . . . . . . . . . . . . . . . 12

6. Average Daily Water Production, Ashley Valley \#4 ............... 13 


\section{EXECUTIVE SUMMARY}

As the oil and gas fields in the United States approach maturity or even abandonment, new methods are being tested to add life to the fields. One area that is being addressed is the reduction of water production. By restricting water production, the pumping, produced fluid separation, and water disposal costs can be reduced. By reducing operating costs, the operator can extend the economic life of a field.

In many fields, including many in the Rocky Mountain region, a very common problem is permeability heterogeneity from matrix variations, fractures, or both. One field where both features exist is the Ashley Valley field in the northeastern Uintah Basin of Utah. In this field, a fracture system connects the oil strata with an underlying, prolific aquifer.

The field experienced early water breakthrough, within two years, as a result of the extensive fracture network. Conventional procedures to remediate the high water rates, including cement squeezing, openhole packers, and liners were unsuccessful.

The objective of this project was to test the viability of using sequential treatment of a production well with a cross-linked polymer to restrict water production from highly permeable and fractured zones. The process proposed for testing in this field was the sequential application of small batches of a cross-linked polymer, chromium (III) polyacrylamide polymer (MarcitK ). First, the highest permeability fractures were to be blocked, followed progressively by the smaller fractures, and finally the higher permeability matrix channels. The initial application of this polymer in September 1997 in the Ashley Valley (AV) well \#2 did increase oil production while decreasing both water production and the relative permeability to water. The successive application of the polymer was considered as a method to increase both daily and ultimate oil production and reduce produced water.

The second polymer treatment was conducted in October 1999 in AV \#2. The treatment consisted of 4,994 barrels of polymer at concentrations ranging from $1,500 \mathrm{mg} / 1$ to $9,000 \mathrm{mg} / \mathrm{l}$. The injection pressures started at $100 \mathrm{psig}$ and increased to $380 \mathrm{psig}$ at the highest concentration. During injection, four offset wells showed polymer breakthrough and were shut in during the remaining treatment. Following a few days of shut-in, all wells were returned to production.

Following treatment, the oil and water production rates for AV \#2 were 14 BOPD and 2,700 BWPD. This was a $44 \%$ decrease in the oil rate and a $40 \%$ reduction in water from the rates after the first treatment. There was also a noticeable decrease in the fluid level in AV \#2, from 2,500 to 3,370 ft. However, there was a corresponding increase in the fluid level $(300 \mathrm{ft})$ in offset AV \#4. 
The second treatment appears to have targeted a different, high-permeability network than the first treatment because the polymer breakthrough pattern at offset producers was different. This indicates that the first treatment was still effective after two years.

The second treatment did not produce an added increase in oil and decrease in water production; both the oil and water production decreased. The decrease in water production did result in a decrease of $20 \mathrm{hp}$ in the size of the electric submersible pump (ESP) in AV \#2, a savings on both utilities and watertreatment chemicals. However, the savings on utilities and chemicals just offsets the decrease in oil production.

The operator has decided that because of the negative results from the second treatment, the conduct of a third treatment will be shelved. However, the possibility of a larger treatment in another well with the shut in of adjacent wells as the polymer is detected is being considered if further treatment is conducted. 


\section{INTRODUCTION}

As the oil and gas fields in the United States approach maturity or even abandonment, new methods are being tested to add life to the fields. One area that is being addressed is the restriction of water production. By restricting water production, the pumping, produced fluid separation, and water disposal costs can be reduced. By reducing operating costs, the operator can extend the economic life of a field.

In many fields, including many in the Rocky Mountain region, a very common problem is permeability heterogeneity. The permeability variation is generally the result of either matrix variations, fractures, or both. One field where both problems exist is the Ashley Valley field. This field has a fracture system that connects the oil strata with underlying Mississippian limestones that are prolific aquifers. Fracture displacement as high as $150 \mathrm{ft}$ has been mapped.

The Ashley Valley field, discovered in 1948, is in the northeastern Uintah Basin of Utah (Figure 1). The field produces a 29.5 EAPI oil from the Pennsylvanian Weber sandstone by means of a prolific edge and bottom water drive. The formation is at a depth of 4,200 ft with an average thickness of $86 \mathrm{ft}$, a porosity of $13 \%$, and a matrix permeability ranging from 1 to $700 \mathrm{md}$. The initial oil saturation was $84 \%$ for an original-oil-in-place (OOIP) estimate of 16.5 MMSTB.

The field experienced early water breakthrough, within two years, as a result of an extensive fracture network that permitted large volumes of water to be produced from the edge water drive and the underlying aquifers. Because of the extensive fracture network, high water cut production was noted regardless of structural position of the well. Attempts to remediate the high water rates involved conventional zone isolation procedures, including cement squeezing, openhole packers, and liners, all of which have been unsuccessful. To handle the high water rates, electric submersible pump (ESP) systems were installed in the 1980s (Larson, et al. 1999).

The existence of the fracture system has been verified by the operator with the use of a backlit, DHV camera. The camera was placed in a well and was effective in providing a visual observation of the fractures, as well as a correlation between remaining mobile oil saturation and matrix permeability in highWOR (water-oil-ratio) environments.

The method proposed to restrict water production was the use of a chromium (III) polyacrylamide polymer (MarcitK )-treatment to first block the high-permeability fractures and then the higher permeability matrix channels. The MarcitK treatment has been used to improve injection well conformance in conventional waterfloods, but has not had much use in production wells, particularly highly fractured ones. The application of the MarcitK treatment was proposed in a sequential manner such that small batches of the polymer would be injected to plug the larger 
fractures first, then progressively smaller fractures with each successive treatment. Time would be allowed between each treatment to allow the polymer to gel.

The rational for this type of treatment was based on the results of an early test of the MarcitK treatment in AV \#2 (Larson, et al. 1999). AV \#2 was treated in September 1997 with MarcitK, eliminating a portion of the fracture flow conduit to bottom water. Originally planned as a 6,300-bbl treatment, only 2,303 bbl of polymer could be placed because of polymer breakthrough at the offset producers. However, the small treatment did increase oil production in the treated well by $32 \%$ (from 19 to 25 BOPD), while decreasing water production by $40 \%$ (2,950 BWPD) (Figures 2 and 3). These results infer a decrease in the relative permeability to water. It was felt that the water production could be further reduced by successive, small applications of MarcitK. The small, successive treatments were to minimize polymer breakthrough to the adjacent wells. The initial treatment did not affect the production of the offset wells.

Positive results from the second treatment would have been an increase in both daily and ultimate oil production and a reduction in produced water. The reduction in produced water would have several positive impacts. If the post-treatment water production were reduced by 1,500 BPD, the existing ESP system could have possibly been replaced with a progressive, cavity-pumping system to increase artificial lift efficiency. Also, there would be a corresponding reduction in treating chemicals in direct proportion to the reduction in water produced. These changes could reduce operating costs by a third per bbl of oil. The environmental impact from the implementation of the project would be a reduction in the volume of produced water discharged at the surface.

\section{EXPERIMENTAL TASKS}

The objective of this project was to demonstrate the sequential treatment of a production well with a cross-linked polymer to restrict water production from highly permeable and fractured zones. Following is a description of the activities completed as part of this project.

\section{Test Design and Well Preparation}

The initial task was the preparation of the well for the treatment series and the design of the treatment. The existing ESP and associated tubing and wire were removed from the well. A packer and tubing string were run into the well and the packer was set above the target zone. The integrity of the well was evaluated through pressure testing.

The treatment was designed to establish a gel injectivity prior to placement of the main, chromium (III) polyacrylamide polymer (MarcitK )-plug. To initiate the treatment, three 200-bbl stages of injection 
with polymer concentration beginning at $1,500 \mathrm{mg} / \mathrm{l}$ and increasing by $1,500 \mathrm{mg} / \mathrm{l}$ to $4,500 \mathrm{mg} / \mathrm{l}$ were

planned. The 200-bbl increments were deemed sufficient to determine the injection pressure response to the increasing polymer concentration. To rapid an increase in the injection pressure would result in a decrease in the polymer concentration. If the injection pressure was acceptable, below the maximum allowable surface pressure of $600 \mathrm{psig}$, the 4,500-mg/l stage would be continued. The planned treatment is shown in Table 1. The injection time was estimated at 5.7 days. This treatment would be the second treatment of AV \#2. Analysis of the test results would dictate further treatment.

\section{Conduct of Treatment}

The polymer treatment was conducted in October 1999 in AV \#2. The actual treatment deviated from the planned treatment because of early polymer breakthrough at some offset wells and the low injection pressures, 100 psig to start and 380 psig at the highest concentration (Figure 4). Because of these factors, the treatment consisted of a larger treatment at the higher polymer concentrations. The actual treatment is shown in Table 1.

\section{Monitoring of Treatment}

Following a short shut-in period after the polymer treatment, the ESP in the target well was replaced and the well was put on test. As testing progressed the ESP was replaced by a smaller sized pump set at a deeper depth. The smaller ESP was selected over a progressive, cavity-pumping system because no vendor would warranty the performance of their progressive, cavity pump at the required volume and depth.

To evaluate the effectiveness of the treatment, the production data from the entire field were collected for more than a year, analyzed, and compared to pretest rates.

\section{RESULTS AND DISCUSSION}

The second polymer injection phase was completed with the placement of 4,994 bbl of highstrength polymer (Table 1). As the treatment was performed in AV \#2, the surrounding production wells were continually monitored for polymer breakthrough. When polymer was detected in a well, the well was shut in until the polymer injection was completed. Four of the wells offsetting the target well experienced polymer breakthrough. The breakthrough pattern was different from the first treatment, indicating that the first treatment was still modifying the subsurface flow patterns.

Four offset wells showed polymer breakthrough during the treatment. The wells and the time to breakthrough were AV \#4 in 4.4 hr, PA \#1 in 7 hr, AV \#5 in 8.4 hr, and HA \#1 in 26.5 hr. 
For AV \#2, the present oil and water production rates are 14 BOPD and 2,700 BWPD. This compares to pretest rates of 22 to 25 BOPD and 4,465 BWPD (Figures 2 and 3). The difference is a $44 \%$ decrease in the oil rate and a $40 \%$ reduction in water from the rates after the first treatment. There has also been a noticeable decrease in the fluid level in AV \#2, from 2,500 to 3,370 ft, but there has been a corresponding increase in the fluid level (300 ft) in offset AV \#4.

The present oil rate is still higher than the projected rate based on the decline curve from 1993 to just prior to the first treatment (Figure 2). The projected value from Figure 4 would be approximately 8 BOPD compared to the present rate of $14 \mathrm{BOPD}$. The present water rate of 2,700 BWPD is considerably lower than the 7,400 BWPD prior to the first treatment.

On a field-wide basis, the first treatment had an effect on both the oil and water production with an increase in oil and a reduction in water. Offset wells AV \#4 (Figure 5) and T.H. Fee \#1 showed some increase in oil production from the first treatment. AV \#4 also showed an increase in water production (Figure 6), which indicates that some of the water from AV \#2 was diverted to AV\#4. The second treatment had little effect on the oil production rates for the offset wells with some showing an increase for a few months following the treatment, but returning to pretreatment rates fairly rapidly. The water production rates for the offsets did not appear to have been affected in the long term by the treatment. Total field rates after the second treatment showed a 10 to 12 BPD decrease in oil production and only a slight decrease in water production.

The decrease in the water rate from the treated well has resulted in a decrease in the size of the ESP by $20 \mathrm{hp}$. There has also been a 44\% decrease in the oil production rate for the target well. On a field-wide basis there has been an oil production decrease equivalent to the decrease in the target well and the only noticeable change in the field-wide water rate is due to the decrease in AV \#2.

\section{CONCLUSIONS}

As stated by Larson et al. (1999), the first polymer treatment of the highly fractured reservoir at Ashley Valley was successful in reducing the water production and increasing oil production. The second treatment appears to have targeted a different, high-permeability network than the first treatment because the polymer breakthrough pattern was different. This indicates that the first treatment was still effective after two years.

The second treatment did not produce an added increase in oil and decrease in water production; both the oil and water production decreased. The decrease in water production did result in a decrease of $20 \mathrm{hp}$ in the size of the ESP in AV \#2, a minimal savings on both utilities and water-treatment chemicals. However, the savings on utilities and chemicals does not offset the decrease in oil production. 
The second treatment did not produce the desired response but did modify the water production and may, in other situations, actually increase the oil production. When a polymer injection is planned in a production environment to modify the production profile, it should be an integral part of the plan to test offsetting wells and shut them in when polymer is detected. It is believed that if this had been done during the first treatment, the results would have indicated a greater reduction in water production and an increase in oil production on a field-wide basis.

The project team decided that the results of this second treatment do not justify any further sequential treatment of AV \#2. Other wells may be evaluated for a single, large treatment with the shut in of adjacent wells as polymer is detected in the well. 


\section{REFERENCES}

Larson, J. B., B. P. Marchant, and G. D. Cotton, 1999, Production Well Water Shut Off Polymer Treatment in the Weber Sandstone - Ashley Valley Field, Uintah County, UT. Presented 1999, SPE Rocky Mountain Regional Meeting, Gillette, WY, SPE \# 55629. 
Table 1. Planned and Actual Treatment Protocols for Ashley Valley Polymer Application

\begin{tabular}{|c|c|c|}
\hline \multicolumn{2}{|c|}{ Planned Treatment } & Actual Treatment \\
\hline Injection & Polymer Conc. & Injection \\
\hline bbl & $\mathrm{mg} / \mathrm{l}$ & $\mathrm{bbl}$ \\
\hline 200 & 1,500 & 200 \\
\hline 200 & 3,000 & 0 \\
\hline 2,600 & 4,500 & $2,300^{\mathrm{a}}$ \\
\hline 2,800 & 6,000 & 214 \\
\hline 200 & 9,000 & 2,080 \\
\hline 200 & 200 Cationic & 200 \\
\hline 100 & Water Overflush & 100 \\
\hline
\end{tabular}

${ }^{a}$ Following this $2,300 \mathrm{bbl}$ was $50 \mathrm{bbl}$ of water and $12.7 \mathrm{hr}$ of shut in to allow blockage to occur and therefore pressure to increase. 


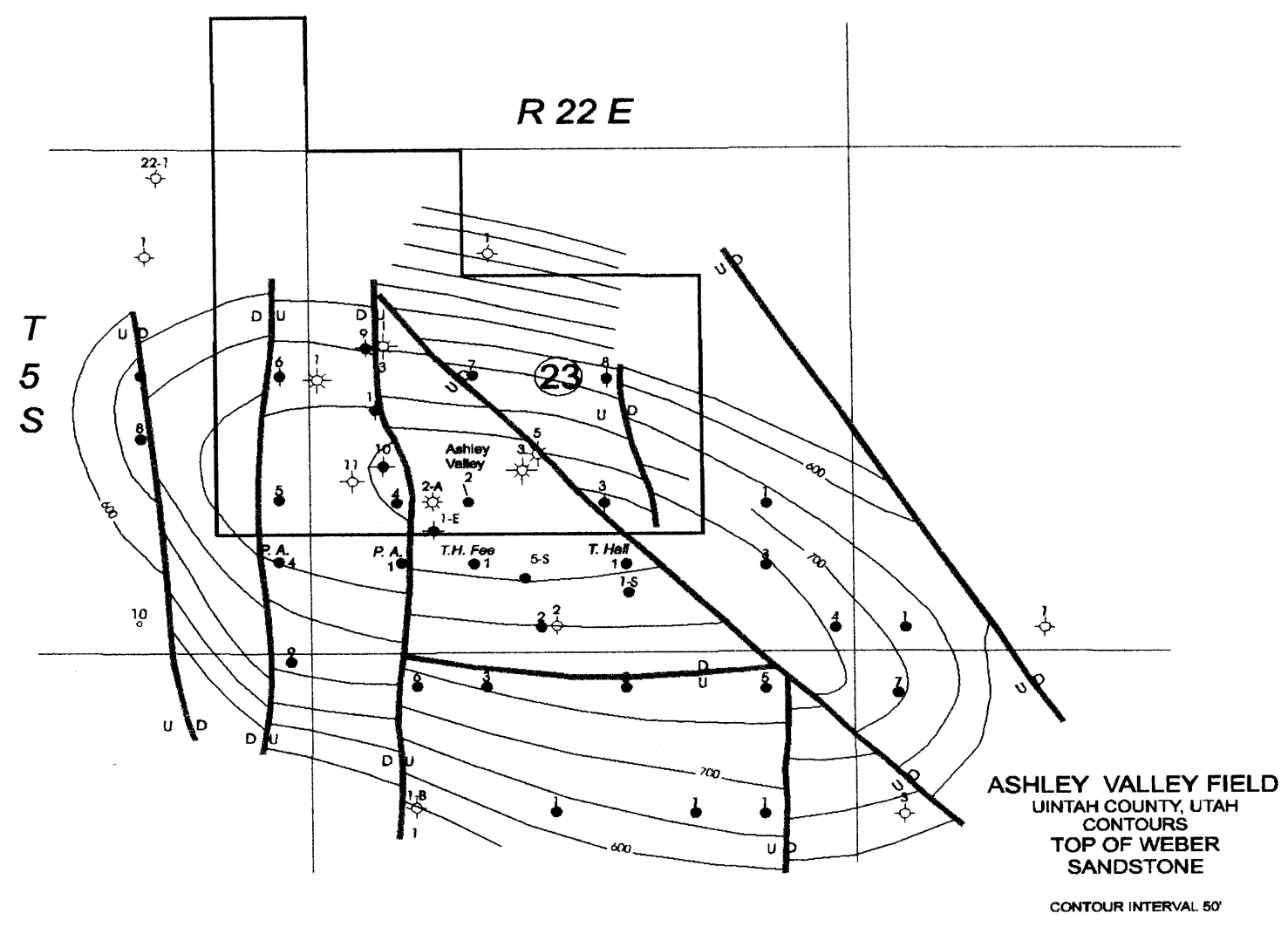

Figure 1. Ashley Valley Field (Larson, et al. 1999) 


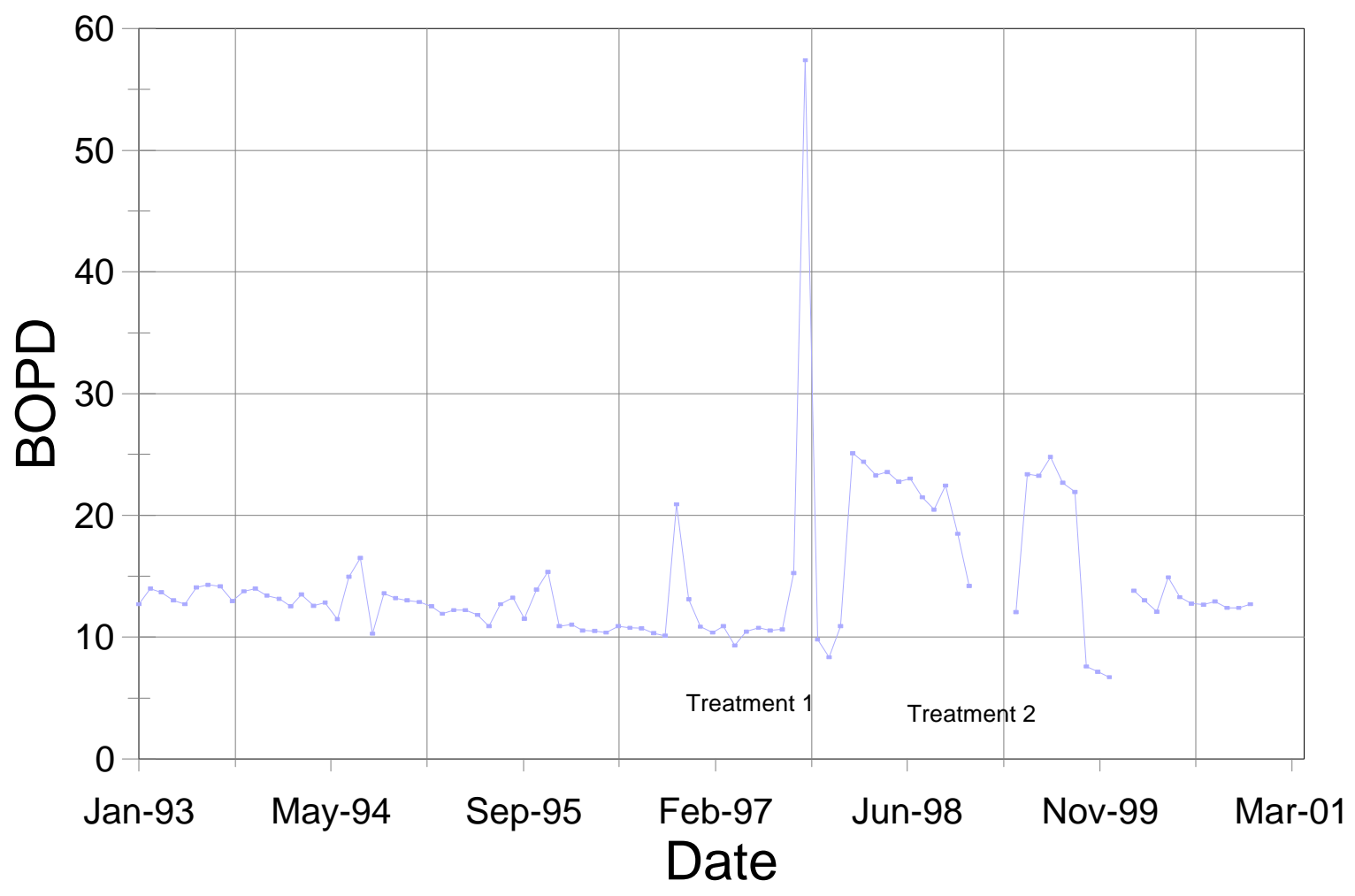

Figure 2. Average Daily Oil Production, Ashley Valley \#2 


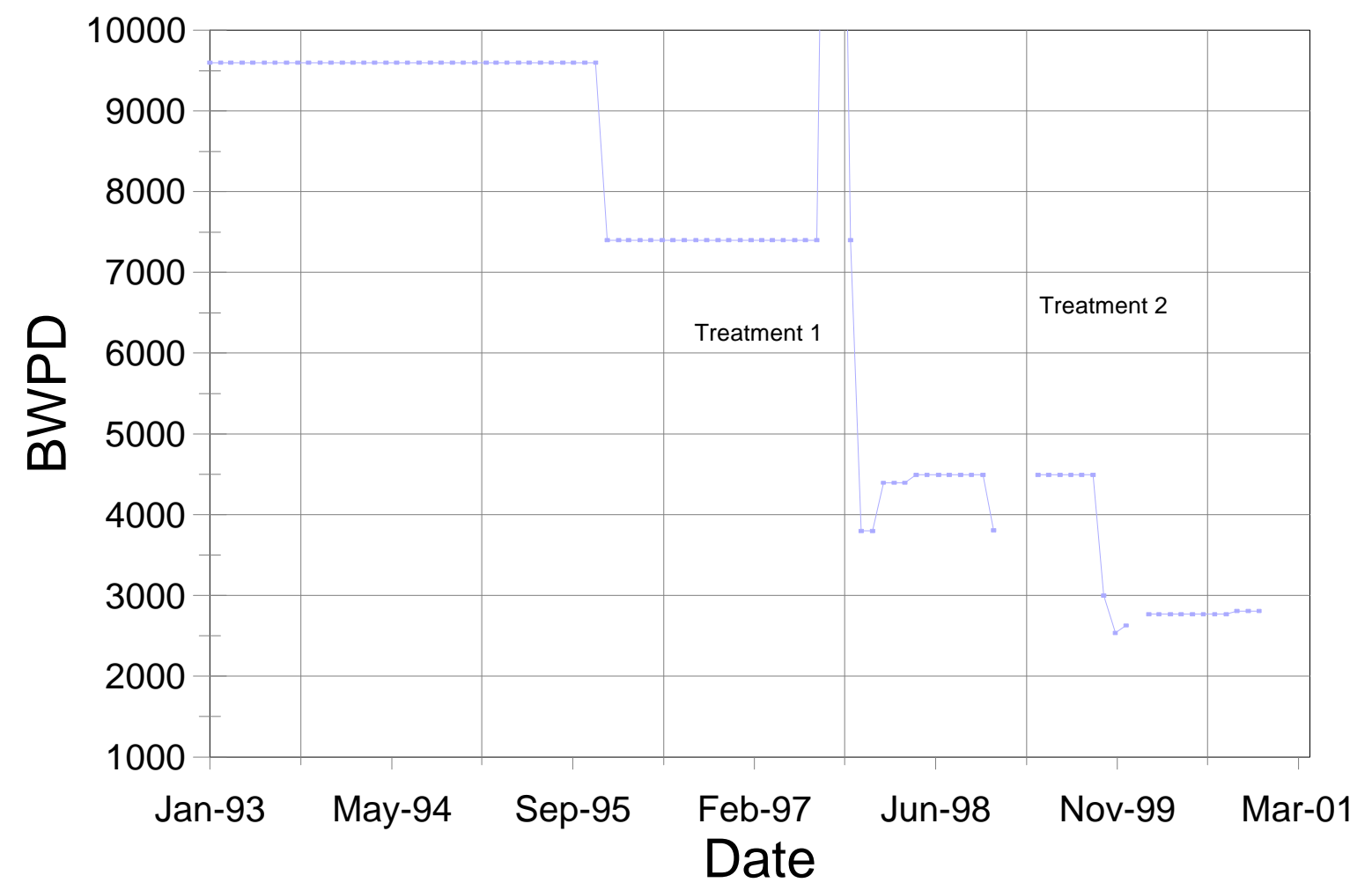

Figure 3. Average Daily Water Production, Ashley Valley \#2 


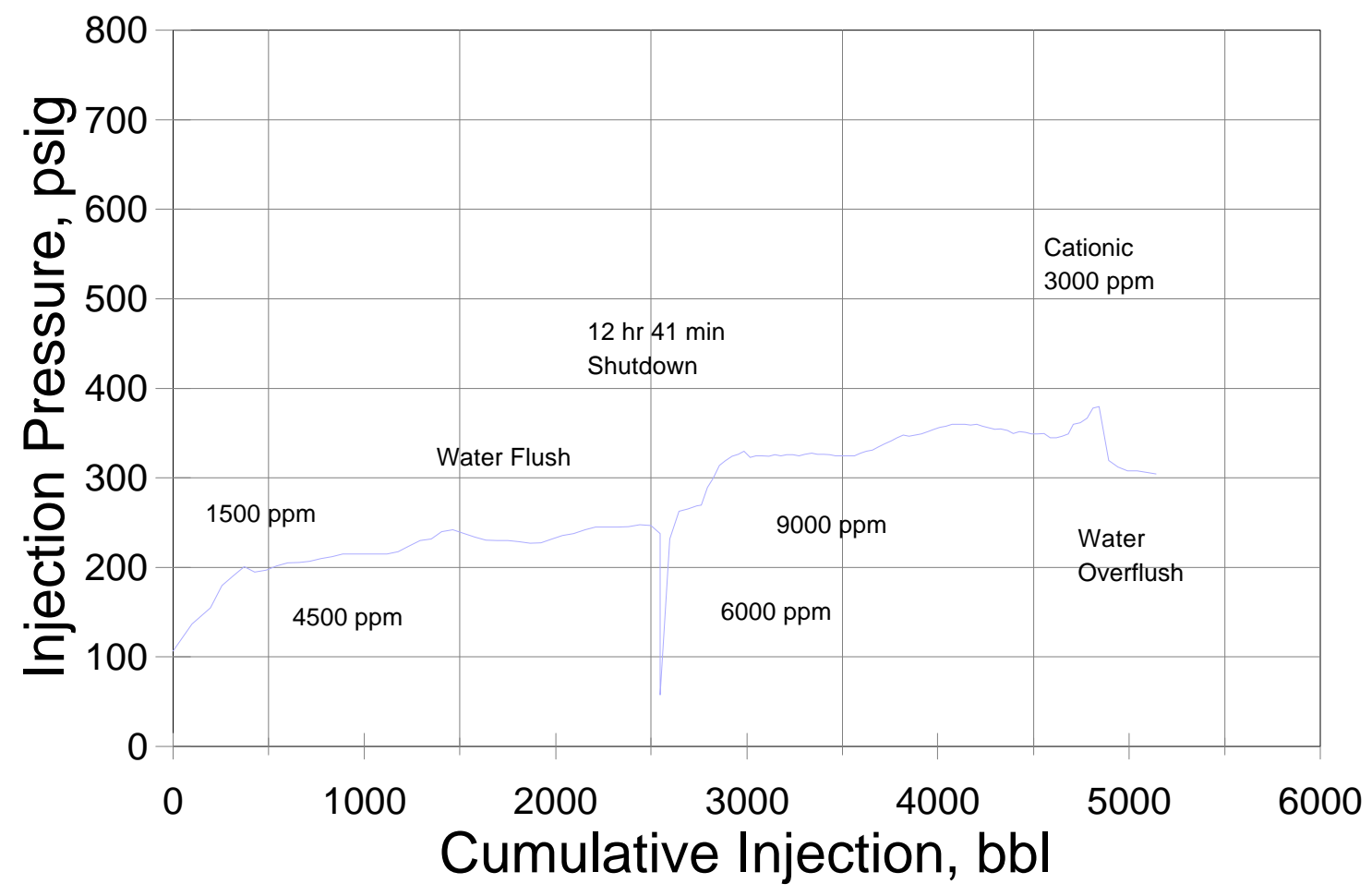

Figure 4. Pressure Profile for Second Polymer Treatment, Ashley Valley Field 


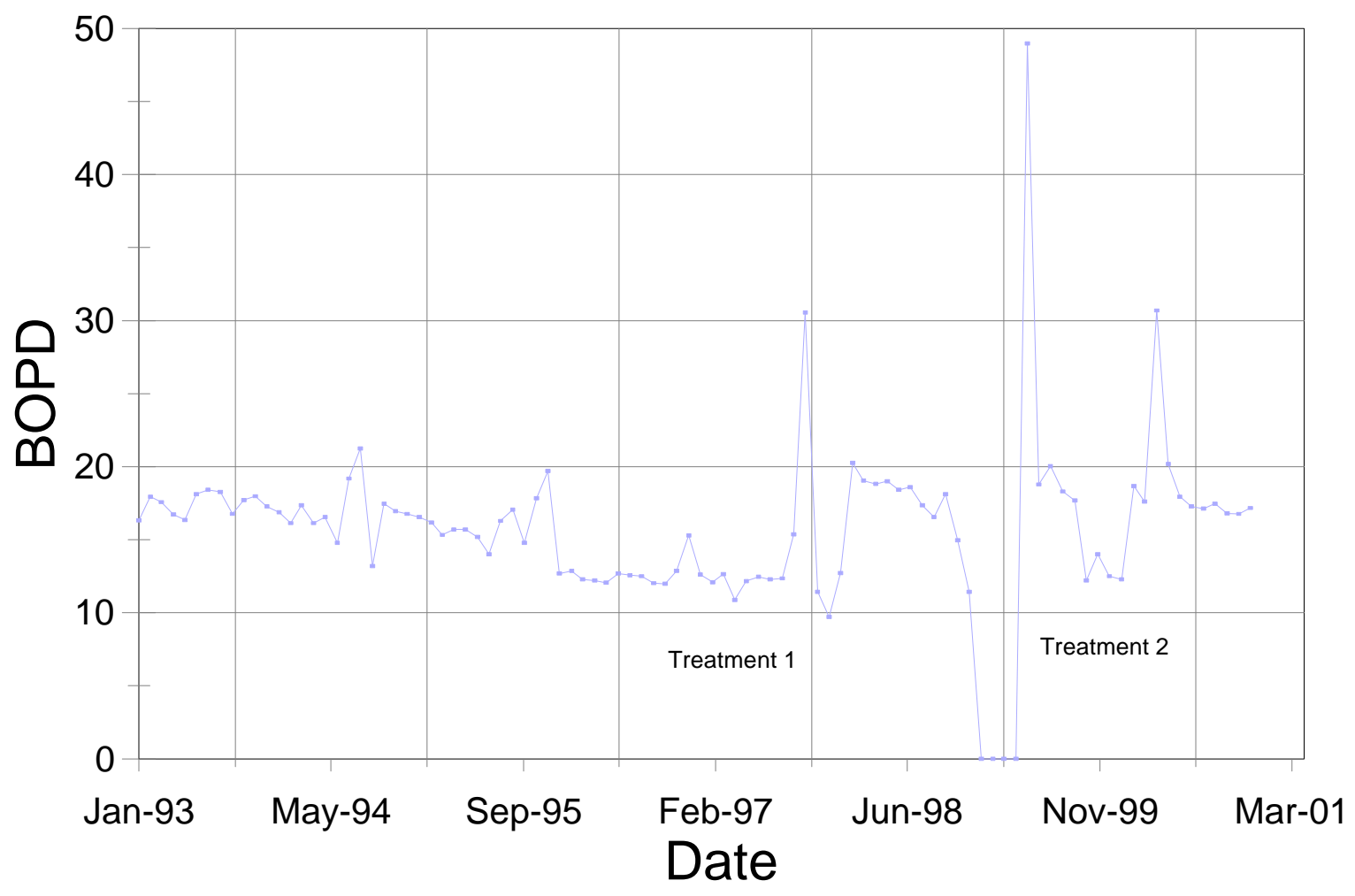

Figure 5. Average Daily Oil Production, Ashley Valley \#4 


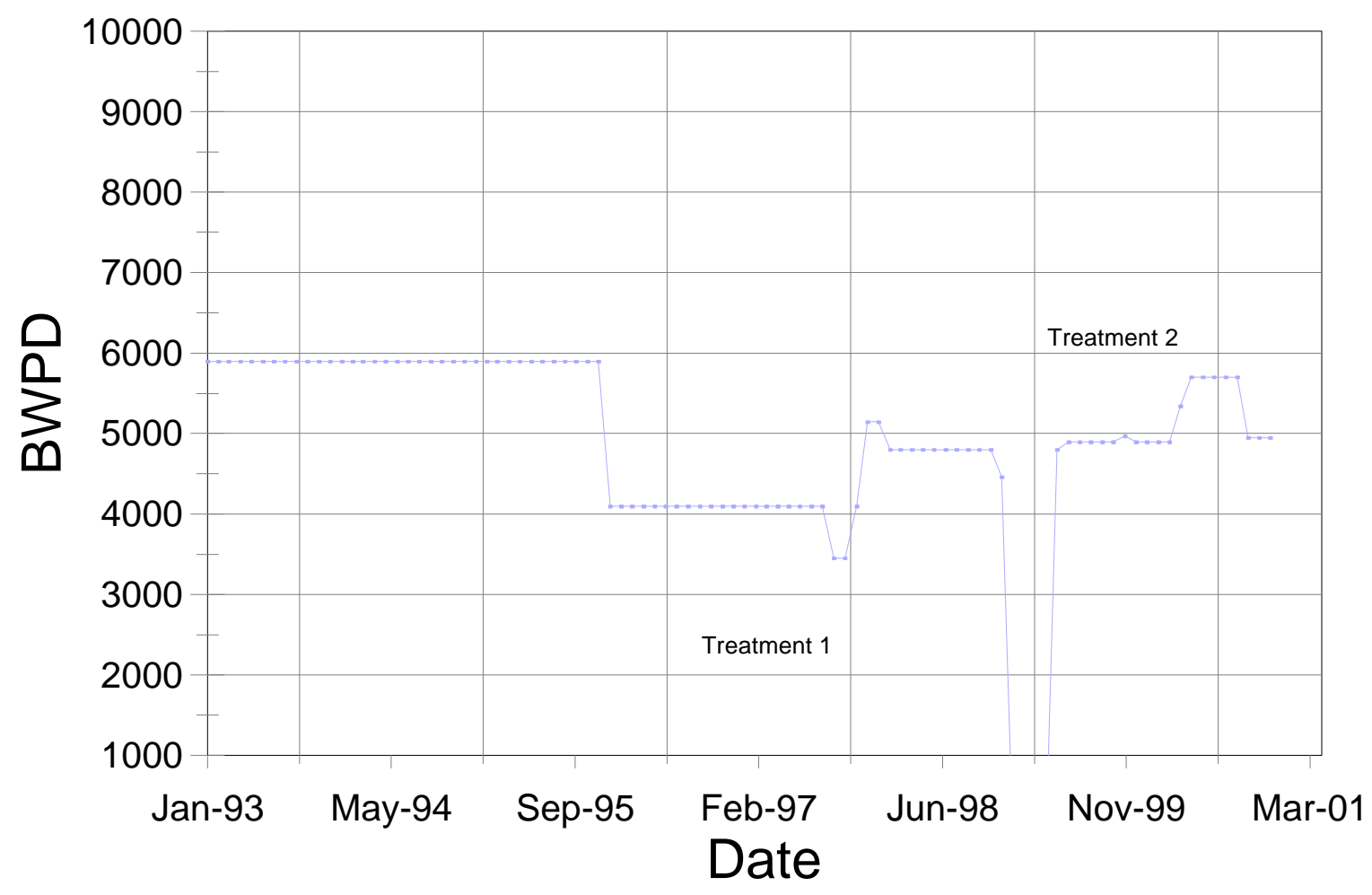

Figure 6. Average Daily Water Production, Ashley Valley \#4 